\title{
Using functional approach in translating arab spring topics: Aljazeera and BBC arabic as study cases
}

\begin{abstract}
In the last two decades there was an increasing interest in the relationship between media translation and ideology. The study sample of this article is the Arab Spring that attracted the attention of various western and Arab media channels like Aljazeera and the BBC. It is reported that each channel may be inclined certain translation strategies that may not necessarily be adopted by the other channel at the same time which entails that the translation in these media outlets is not random and unbiased. Therefore, the findings of the current work will be helpful for translators that are working in such media institutions.
\end{abstract}

Keyword: Arab spring; Media translation; Functional theory; Ideology; Aljazeera; BBC 